УДК 528:004

DOI: $10.33764 / 2687-041 X-2021-3-36-39$

\title{
ОСОБЕННОСТИ ОЦЕНКИ ГУДВИЛЛА В УСЛОВИЯХ ЭКОНОМИЧЕСКОГО КРИЗИСА
}

\section{Владимир Викторович Павленко}

Сибирский государственный университет геосистем и технологий, 630108, Россия, г. Новосибирск, ул. Плахотного, 10, обучающийся, тел. (999)462-11-65, e-mail: f50.pro@yandex.ru

\section{Оксана Владимировна Крутеева}

Сибирский государственный университет геосистем и технологий, 630108, Россия, г. Новосибирск, ул. Плахотного, 10, кандидат экономических наук, доцент кафедры цифровой экономики и менеджмента, тел. (383)361-01-24, e-mail: frans_pays@mail.ru

В статье рассматривается гудвилл с точки зрения его обесценивания, а также основные проблемы, препятствующие достоверной количественной оценке данного актива, указывается необходимость в тестировании гудвилла в определенных ключевых точках жизненного цикла предприятия.

Ключевые слова: гудвилл, деловая репутация, обесценивание, методы оценки, рыночная стоимость бизнеса, справедливая стоимость бизнеса

\section{FEATURES OF GOODWILL ASSESSMENT IN THE CONTEXT OF THE ECONOMIC CRISIS}

\section{Vladimir V. Pavlenko}

Siberian State University of Geosystems and Technologies, 10, Plakhotnogo St., Novosibirsk, 630108, Russia, Student, phone: (999)462-11-65, e-mail: f50.pro@yandex.ru

\section{Oksana V. Kruteeva}

Siberian State University of Geosystems and Technologies, 10, Plakhotnogo St., Novosibirsk, 630108, Russia, Ph. D., Associate Professor, Department of Digital Economy and Management, phone: (383)361-01-24, e-mail: frans_pays@mail.ru

The article considers goodwill from the point of view of its depreciation, as well as the main problems that impede a reliable quantitative assessment of this asset, indicates the need for goodwill testing at certain key points of the life cycle of the enterprise.

\section{Введение}

Понятие гудвилла стало широко распространяться в оценочной практике, начиная с 80-х годов прошлого века. Гудвилл (или деловая репутация) понимается как величина дисконтированной стоимости будущих прибылей предприятия. И.Е. Бельских и И.М. Сметанин отмечают следующие ключевые характеристики: отсутствие материально-вещественной формы, существование за счет преимуществ, присущих той или иной организации, необходимость в учете и оценке только в случае сделки о купле-продаже бизнеса [1]. 
Рассмотрим ряд проблем, связанных с количественной оценкой гудвилла. Первая и существенная проблема - это отсутствие единого мнения, как в литературе, так и в нормативно-правовом законодательстве нашей страны по поводу единой трактовки данного термина. Этот факт отражен в работе [4], причем деловая репутация и гудвилл могут быть рассмотрены и как синонимы, и как различные по сути определения. Деловая репутация может быть оценена как чисто внешний актив компании, качественную оценку которому дают контрагенты, поставщики или сами потребители. В отношении гудвилла характерно, что он признается часто внутренним неотчуждаемым активом компании, который может быть текущим или приобретенным в результате слияния компаний. Преобладает подход, согласно которому деловая репутация является частью гудвилла, которого мы будет в дальнейшем придерживаться.

Вторая проблема связана с обесцениванием стоимости гудвилла в результате снижения справедливой стоимости после приобретения компании [6]. В 2004 году был введен международный стандарт финансовой отчетности (МСФО) IFRS 3 «Объединение предприятий», где предписывалось проводить ежегодное тестирование гудвилла на обесценивание и отказаться от его амортизации, тем самым признавая данный актив неубывающим активом.

Новый порядок исчисления стоимости гудвилла, исходя из его обесценивания, значительно трансформировал модели и методы его оценки [3]. Появилась необходимость в учете возможных финансовых рисков для покрытия потерь [2], а также в анализе факторов, влияющих на величину справедливой стоимости бизнеса.

\section{Основная часть}

В качестве ключевых факторов, влияющих на величину изменения справедливой стоимости, выделяют:

- наличие «сгенерированного запаса прочности» гудвилла и прочих нематериальных активов, что замедляет процесс обесценивание и приводит к временным и стоимостным разрывам;

- величину амортизационного фонда, формируемая за счет отчислений от приобретенных нематериальных активов, создающая дополнительную «подушку безопасности»;

- влияние внешней среды на обесценивание, за счет чего формируется запаздывающий эффект - изменение рыночной стоимости компании провоцирует изменение стоимости гудвилла, а не наоборот;

- нежелание самих компаний признавать факт обесценивания гудвилла.

Существует большое количество методов, применяемых для оценки стоимости гудвилла, которые можно разделить на две группы: качественные и количественные.

В первую группу будут входить методы, которые часто используются для оценки бренда: методы функции желательности Харрингтона, метод управления репутацией Rep Trap Pulse, использование индексов устойчивого развития Доу Джонса, модель Bav [3]. 
Ко второй группе относятся: метод определения избыточной прибыли, модель Эдвардса-Белла-Ольсона, модель реальных опционов, оценка, производимая на основании объемов реализованной продукции и показателя рыночной капитализации, метод избыточных ресурсов, квалиметрический метод, метод на основе расчета левериджа [4].

\section{Результаты}

Рассмотрим на примере крупной IT-компании Сибирского региона механизм обесценивания гудвилла. В условиях кризиса финансовая устойчивость в данной сфере зависит напрямую от спроса на услуги со стороны большого количества заинтересованных лиц: торговых площадок и представительств, заказчиков, субподрядчиков, рекламных агентств, клиентов.

ООО «Альвента» является официальным представителем компании КонсультантПлюс в Новосибирске, в том числе имеются филиалы еще в шести регионах страны: Москве, Саратове, Омске, Барнауле, Томске и Красноярске. Вид деятельности - установка и обслуживание справочной системы. В 2016 году компания расширила свои представительства на два региона, в результате чего приобрела дополнительную клиентскую базу. Мы видим, как изменяется стоимость гудвилла с течением времени под влиянием фактора масштабирования бизнеса.

Проведем тестирование гудвилла путем сравнения его возмещаемой стоимости с балансовой на основании рекомендаций МСФО (IAS) 36 «Обесценение активов». Стандарт использует понятие единицы генерирования денежных средств, в качестве которых будут выступать сегмент технической разработки и сегмент маркетинговых исследований. Приобретенный гудвилл на момент расширения бизнеса составил 14800 тыс. руб. В результате распределения его стоимость можно отобразить в виде следующей пропорции: $5900: 8900$. В 2019 году была произведена переоценка возмещающей стоимости сегмента технической разработки в размере 19771,6 тыс. руб., балансовая стоимость составила 27000 тыс. руб.

Расчетные данные представлены в таблице.

Расчет определения величины обесценивания гудвилла сегмента технической поддержки ООО «Альвента» в 2019 году, тыс. руб.

\begin{tabular}{|c|r|r|r|}
\hline Показатели & \multicolumn{1}{|c|}{ На начало года } & Обесценивание & На конец года \\
\hline Гудвилл & 5900,0 & $-5900,0$ & 0,0 \\
\hline Активы & 22995,0 & $-3232,0$ & 9,6 \\
\hline $\begin{array}{c}\text { Нематериаль- } \\
\text { ные активы }\end{array}$ & 10,0 & $-1,4$ & - \\
\hline $\begin{array}{c}\text { Дебиторская } \\
\text { задолженность }\end{array}$ & - & - & 19763,0 \\
\hline Итого & 28905,0 & 9133,4 & 1976 \\
\hline
\end{tabular}


Последовательность расчетов следующая: балансовая стоимость представляет собой сумму всех активов и гудвилла, т.е. 28905 тыс. руб. Сравнение балансовой и возмещающей стоимости показало наличие убытка от обесценивания в размере - 2105 тыс. руб. Распределение оставшейся суммы, а именно 3795 тыс. руб. осуществляется на основании доли каждого вида активов в общей балансовой стоимости генерирующей единицы.

\section{Заключение}

По нашему мнению, выбор метода оценки гудвилла будет зависеть от целей оценки. Так внешний или приобретенный гудвилл в результате продажи должен оцениваться пропорциональным методом, а текущий или внутренний гудвил по методу обесценивания его стоимости.

Гудвилл рассматривается как объект оценки исходя из следующих предположений:

- деловая репутация компании имеет экономическую природу, которая характеризуется наличием высококвалифицированных сотрудников, хорошей кредитной историей, грамотной сбытовой политикой;

- деловая репутация зависит от финансовой устойчивости компании;

- деловая репутация включатся в стоимость действующего бизнеса, следовательно, является неотделимой его частью.

\section{БИБЛИОГРАФИЧЕСКИЙ СПИСОК}

1. Бельских И.Е., Сметанин И.М. Учет и оценка гудвилла: мировой опыт и Российская специфика // Международный бухгалтерский учет. 2010. №3. С.24-29.

2. Вдовин С.А. Проблемы оценки экономической эффективности участников рынка в современных реалиях цифровой экономики // Экономика: вчера, сегодня, завтра. 2018. Т. 8. № 2А. С. 114-119.

3. Калинский О.И., Михайлова О.Ю. Использование функции желательности Харрингтона для качественной оценки деловой репутации (гудвилла) предприятия (на примере российских металлургических заводов) // Бюллетень науки и практики. 2016. №1. С.25-32.

4. Ковалева Н.А., Шубат О.М. Анализ методов оценки внутренне созданного гудвилла // XII Международная конференция «Российские регионы в фокусе перемен». С. 605-616.

5. Мокрова Л.П., Косорукова И.В. Инструменты управления деловой репутацией бизнеса и ее стоимостью // Имущественные отношения в РФ. 2018. №9 (204). С.18-30.

6. Неклюдова В.Л., Вдовин С.А. Математический механизм расчета тарифа достаточного для покрытия потерь от экономических, финансовых и инвестиционных рисков // Инновации и инвестиции. 2019. № 5. С. 154-157.

7. Плотников В.С., Плотникова О.В. Оценка обесценения гудвилла и возмещение потерь от обесценения в консолидированной финансовой отчетности // Международный бухгалтерский учет. 2015. №5 (347). С.25-37.

8. Пузыня Н. Ю. Особенности оценки гудвилла как стоимости деловой репутации фирмы // Имущественные отношения в РФ. 2006. №2. URL: https://cyberleninka.ru/article/n/osobennostiotsenki-gudvilla-kak-stoimosti-delovoy-reputatsii-firmy (дата обращения: 15.11.2020).

9. Столбова О.Л., Сизова А.О. Проблемы государственной регистрации прав на землю и иную недвижимость в России // Интерэкспо Гео-Сибирь. 2013. Т. 6. № 1. С. 173-175.

(C) В. В. Павленко, О. В. Крутеева, 2021 